\title{
Innovative education at postgraduate level: Flipped classroom
}

\author{
Pilar Moreno-Crespo ${ }^{1, *}$, Celia Corchuelo-Fernández ${ }^{2}$, Aránzazu Cejudo-Cortés ${ }^{2}$, and Coral \\ I. Hunt-Gómez ${ }^{1}$ \\ ${ }^{1}$ University of Sevilla, Pirotecnia, 19, Sevilla 41013, Spain \\ ${ }^{2}$ University of Huelva, Avenida Tres de Marzo s/n, Huelva 21071, Spain
}

\begin{abstract}
The educative innovation presented was developed at the Official University Master of Psychopedagogy at the University of Seville, Spain. An approximation to the Flipped Classroom methodology was carried out. Postgrad students are not normally exposed to this methodology, and therefore, they were not familiarised with it. To implement it, firstly, the class was divided into groups and, from a selection of the curricular contents of the subject; each group was assigned a particular topic. Each group had to prepare a presentation in which three tasks were to be fulfilled: the creation of an explanatory video to be projected during a presentation session with the aim of illustrating the theoretical contents, a reinforcement activity to enhance meaningful learning and an assessment of the presentation made. At the end of the study, the subjects received a questionnaire to analyse their degree of satisfaction according to the methodology. Results showed that the methodology was perceived as satisfactory or very satisfactory by most of the participants.
\end{abstract}

\section{Introduction}

In this paper we present an approximation to the Flipped Classroom methodology. This is a teaching innovation project approved by the University of Huelva (2018/19). The team working in this project is interdisciplinary and there are experts in different fields from three Andalusian universities: the University of Seville, the University of Huelva and the University Pablo de Olavide.

The teaching innovation project aims to develop the methodology of the flipped classroom in the different subjects taught by the members of the research team during the academic year 2018/19. During the development of the course some specific sessions have been carried out in a generalized way throughout the subject. The methodology of the flipped classroom was tested during the academic year and, in this sense, its viability of adapting the traditional methodology to the flipped classroom was validated.

\footnotetext{
*Corresponding author: pmcrespo@us.es
} 
The presented teaching innovation is justified by the transformations it seeks to achieve. These transformations are considered to be a clear improvement at Degrees, Faculty and University level. The transformations that were hoped for were the following:

- Meeting the requirements of the European Higher Education Area (EHEA): The focus needs to be on enhancing the role of students in their own learning process. The student must be a manager and producer of knowledge, leaving aside the vision of a student body that is exclusively receptor.

- Creating working networks: The assessment and the incorporation of innovative methodological strategies into teaching practice in many occasions are carried out on individual basis. With this project, we intend to consolidate a working group that includes professionals from other Universities, who provide an improvement in teaching practice. Collaboration and exchange networks were to be established.

- Transforming methodologies: The study aims to develop an improvement in teaching methodology that lasts over time, in such a way that, if the methodology of the flipped classroom is valued positively, it can be developed in a more detailed way and maintained over the years.

- Improving the teaching practice: We consider that teamwork will have an impact on the improvement of qualifications from the point of view of quality.

We must state that flipped classroom is [1] "[...] learning strategy that offers preparatory or core content outside the classroom and uses class time for active learning" (p. 2). The Flipped Classroom procedure is based on the premise that the student body performs preparation tasks before class. In the Flipped Classroom model there are a number of tasks that the student must perform before starting the class. Classes are mainly used to enhance meaningful learning [2-4]. Several studies affirm that active methodologies such as the flipped classroom improve participation, learning, educational results, among many other advantages. [1, 5-7]. The teacher has more prominence as a companion or advisor. Teaching is more personalized. In other words, [8] " [...] students can access to learning, contents related to the new topics that they will learn through such materials as lecture videos outside the classroom where they have face-to-face classes" (p. 251).

\section{Teaching innovation project}

The educative innovation was carried out during the academic year 2018/2019. The final sample was composed of 50 students. It was realized in Official University Master of Psychopedagogy at the University of Seville. Data were collected in the following optional subjects:

- Guidance and Psychopedagogical Action in the Socio-Community Context

- Methods of Guidance

The educative innovation took place during the academic year 2018/2019 in the optional subjects "Guidance and Psychopedagogical Action in the Socio-Community Context" and "Methods of Guidance" of the Official University Master of Psychopedagogy at the University of Seville, Spain. As the subjects were optional, there were less than 35 members per group. The final sample was composed of 50 students. This number of students made the innovation was significant enough to include the subjects in a Teaching Innovation Project 2018/2019, financed by the University of Huelva with its main focus on the Flipped Classroom methodology. The team working in this project was interdisciplinary 
and there were experts in different fields from three Andalusian universities: the University of Seville, the University of Huelva and the University Pablo de Olavide.

\subsection{The educative innovation was developed in several sessions}

\subsubsection{First session.}

The presentation and introduction of the development of the subject is carried out in the first weeks. The teacher had to explain the basic information regarding the subject such as the lecturers, methodology, and assessment. The session was focussed on the description of the Flipped Classroom methodology and two explanatory types of videos were shown: 1) Didactic videos in which the Flipped Classroom methodology was explained, and 2) Videos created by students from other subjects and degrees, to be used as models. At the end of the session, the class was divided into groups and, from a selection of the curricular contents of the subject; each group was assigned a particular topic.

\subsubsection{Second, third and fourth sessions.}

Lectures were guiding the sessions according to the Flipped Classroom methodology. In the first place, a video with the theoretical content was projected with the aim of illustrating the theoretical contents; a reinforcement activity to enhance meaningful learning and an assessment of the presentation was made. The objective of this is showing the students the kind of activities they need to prepare. Students are given time to plan the group working as well as to record their video.

\subsubsection{Following sessions.}

Students made their presentations in their assigned class sessions. Each workgroup had to plan a one-hour class session where they should: 1) Project a video with the theoretical content to expose with a maximum of ten minutes of duration; 2) The class group is dynamized with an activity or dynamic oriented to promote significant learning (it is intended to be a fun and relaxed activity); and 3) the students have to design and apply an evaluation on their own presentation focusing attention on one or several aspects they have previously selected (the learning encouraged, the development of the activity, the video, etc.).

\subsubsection{Final session.}

Students sat an exam about the theoretical content studied. We must point out that all the students enrolled in the subjects developed following the methodology of the classroom turned over passed the subject with a remarkable use of the learning carried out.

\section{Results}

Once all sessions were completed, subjects received a questionnaire METFLIPP. Results showed that the methodology was perceived as satisfactory or very satisfactory by most of the participants. When asked about the necessity of including active methodologies in university subjects, with students participating in the complete working process -from theory to practice-; participants mostly provided a positive answer. In the same way, 
sessions developed and carried out by the students were positively received and the satisfaction levels obtained were high.

In response to the question Globally value what this experience has been for you (Table 1), students value the experience as satisfactory at $52.2 \%$. Together with the $8.7 \%$ that indicates that the experience has been very satisfactory, it adds up to a majority of $60.9 \%$. Although it was highly positive, $19.6 \%$ rated the experience as "Unsatisfactory", 13- rated it as "Indifference" and $6.5 \%$ as "Very unsatisfactory". Therefore, we propose to review the processes followed during the development of this active methodology with the aim of perfecting those aspects that have led students to negatively value the experience, even if in a minority way. One of the aspects that the research team considers important is that the student body should be aware that the effort made is aimed at promoting significant learning, since it has been detected that the student body considers that the relationship between the volume of work and the learning results are unequal. There is, therefore, a kind of devaluation of the effort made, which does not take into account that the learning developed has a high level of significance and durability.

Table 1. Globally value what this experience has been for you.

\begin{tabular}{|c|c|c|}
\cline { 2 - 3 } \multicolumn{1}{c|}{} & Frecuency & $\%$ \\
\hline $\begin{array}{c}\text { Very } \\
\text { satisfactory }\end{array}$ & 4 & $8.7 \%$ \\
\hline Satisfactory & 24 & $52.2 \%$ \\
\hline Indifference & 6 & $13 \%$ \\
\hline Unsatisfactory & 9 & $19.6 \%$ \\
\hline $\begin{array}{c}\text { Very } \\
\text { unsatisfactory }\end{array}$ & 3 & $6.5 \%$ \\
\hline
\end{tabular}

In response to the question, Do you consider it necessary for other university subjects to use a participatory methodology? (Table 2), 65.3\% of those surveyed believe that it is a useful and profitable methodology to improve the teaching of any subject. $22.4 \%$ consider that the participatory methodology is useful but only for very few subjects. On the other hand, $6.1 \%$ consider that participatory methodologies are useful and profitable methodology to improve the teaching of any subject. $4.1 \%$ consider that the participative methodology is not adequate for any subject taught at the University. $2 \%$ state that they are indifferent if one methodology or another is used. Bearing in mind that the degrees that have participated in the study are to a greater or lesser extent involved in professions related to teaching or education in general, we understand that students value positively the use of alternative methodologies to traditional ones. In this way they have a tendency towards active and participative methodologies that strengthen the protagonist of the student and the promotion of a critical attitude and questioning reality. 
Table 2. Do you consider it necessary for other university subjects to use a participatory methodology?

\begin{tabular}{|c|c|c|}
\cline { 2 - 3 } \multicolumn{1}{c|}{} & Frecuency & $\%$ \\
\hline Yes, it is a useful and profitable methodology to improve the teaching of any \\
subject. & 32 & $65.3 \%$ \\
\hline Yes, it is useful but only for very few subjects & 11 & $22.4 \%$ \\
\hline I do not consider this methodology adequate for any subject & 2 & $4.1 \%$ \\
\hline I'm indifferent to one methodology or another. & 1 & $2 \%$ \\
\hline Yes, it is a useful and profitable methodology to improve the teaching of any \\
subject.
\end{tabular}

\section{Conclusions}

In conclusion, it should be noted that the level of applications for the Official Master's Degree in Psychopedagogy has influenced the progression of the methodology chosen for the subjects.

We must point out the implication of the Information and Communication Technologies society in the development of a methodology that supposes an active and directed effort of the students. In a negative way, the new generations are used to receiving prizes, stimuli, and answers in the immediacy of their communication device. We have found that the need for immediacy clashes with the development of a job that involves time, effort, dedication and organization. Students find themselves with an "academic investment" to which they is not accustomed, in order to arrive at a result (in the form of a grade) which in other subjects they achieves with much less effort. The student does not distinguish between significant learning and traditional learning, because it uses the unit of measurement of the grade and not the quality of the learning.

However, the level of involvement of the subjects was positive and the experience obtained a high degree of satisfaction.

It is also important to note that the volume of content worked during the project was remarkable. The students were motivated in the elaboration of the videos, the planning of the sessions, as well as in the evaluations. Self-directed class sessions were examples of creativity and participation. Many of the students were satisfied with the atmosphere of complicity established in the classroom.

Bearing in mind the significant level of learning established with the development of the flipped classroom, the students have proposed the improvement of the evaluation system replacing the standard exam with other evaluation methodologies. In the future, it is planned to include different final evaluation instruments, such as creative or digital portfolios.

\section{References}

1. L. Cobb, C. Steele, Exploiting the fringe: flipping, microcredentials, and MOOCs, Carrboro, NC, Tagoras (2014). 
2. J.P. Smith, The efficacy of a flipped learning classroom (Doctoral dissertation, McKendree University, Illinois, 2015).

3. J. O'Flaherty, C. Phillips, The use of flipped classrooms in higher education: A scoping review, The Int. And High Educ., 25 (2017).

4. J. Bergmann, J., A. Sams, Flipped learning: Gateway to student engagement, (International Society for Technology in Education, 2014).

5. S. Freeman, S.L. Eddy, M. McDonough, M.K. Smith, N. Okoroafor, H. Jordt, et al., Active learning increases student performance in science, engineering, and mathematics, Proceedings Nat. Aca. Scie., 23 (2014).

6. R. Yilmaz, Knowledge sharing behaviors in e-learning community: Exploring the role of academic self-efficacy and sense of community, Comp. In Hum. Beh., 63 (2016).

7. S. Sandrone, J.V. Berthaud, C.Carlson, J. Cios, N. Dixit, A. Farheen, J. Kraker, J. W.M. Owens, G. Patino, H. Sarva, D. Weber, L.D. Schneider, Education Research: Flipped classroom in neurology, Neurol., 93 (2019).

8. R. Yilmaz, Exploring the role of e-learning readiness on student satisfaction and motivation in flipped classroom, Comp. In Hum. Beh., 70 (2017). 